\title{
Simulation of the water cycle in Biosphere 2
}

\author{
Daeseok Kang * \\ Department of Environmental Engineering Sciences, University of Florida, Gainesville, FL 32611, USA
}

Received 5 April 1997; received in revised form 2 July 1998; accepted 9 July 1998

\begin{abstract}
The budget of water flows and storages in Biosphere 2 was drawn in energy systems language to generate equations for a simple simulation model. Using data by others for calibration and a seasonal variation of sunlight, main features of the seasonal water cycle were analyzed. The model result coincided with the observed patterns of seasonal variation in the water level of primary storage. Primary storage was more affected by changes in water management, while other storages were mostly controlled by sunlight energy. A stable isotope model of water species simulated the trends in isotopic fractionation in agreement with observations. Isotopic compositions of the reservoirs reached steady state and were close to the measured values. (C) 1999 Elsevier Science B.V. All rights reserved.
\end{abstract}

Keywords: Water cycle; Stable isotope; Isotopic fractionation; Simulation models; Biosphere 2

\section{Introduction}

The circulation of water within Biosphere 2 at Oracle, Arizona is an operating model for the water cycle of the whole earth. Tubiello et al. (1999) presented the water management system and quantified the amounts of water circulating in the system. In this supplement, an overview model is developed using these data for calibration, to simulate seasonal patterns of water and its isotopes.

By circulating through various reservoirs, water plays an important role in the dynamics of the earth's surface and life on it. It acts as a weathering and erosion agent, and transports materials on land and in the oceans. It also contributes to determine ecosystem patterns and distribution on earth. Sunlight energy drives the

\footnotetext{
* Corresponding author. Present address: Eunha C-202, Noryangjin-1-dong, Dongjak-ku, Seoul, (South) Korea, 156-051. Tel.: + 822823 6360; e-mail: dskang@hanimail.com
} 
water cycle, mainly by evaporating water from land and oceans, and transporting it as water vapor in the atmosphere.

Water molecules have several different isotopic species because of three stable isotopes $\left({ }^{16} \mathrm{O},{ }^{17} \mathrm{O}\right.$, and $\left.{ }^{18} \mathrm{O}\right)$ of oxygen and two stable isotopes $(\mathrm{H}$ and $\mathrm{D})$ of hydrogen which occur in nature. Natural abundance of isotopic species of water varies at various stages of water cycle primarily as a result of fractionations caused by phase transitions, chemical or biological reactions, and transport processes (Gat, 1980). Slight variations in the physical and chemical properties of isotopes produce isotopic fractionation, which is proportional to differences in their masses (Faure, 1986). Distribution of isotopic molecules of water in various phases has been used to study the dynamics of natural waters and their history.

In the materially closed system of Biosphere 2, the water system integrates natural and mechanical sub-systems to provide internal circulation of water through several different reservoirs. Understanding of the hydrologic cycle of Biosphere 2 is important for effective operation and management of this facility. Also, the much faster and smaller scales of the Biosphere 2 system, compared to the whole earth, could provide insight on the planet's hydrologic cycle.

\section{A model of water cycle in Biosphere 2}

Tubiello et al. (1999) characterized the water cycle of Biosphere 2 with a simple model that has five major reservoirs; ocean, soil water, primary storage, condensation tanks, and atmospheric vapor. They identified three different cycles of water circulation with different time scales; fast pool associated with the air handler's condensation system and evapotranspiration ( $60 \%$ of the water used daily), medium pool associated with soil drainage $(30 \%)$, and slow pool associated with the ocean $(10 \%)$.

Fig. 1 is an energy systems language interpretation of the simplified model of the water cycle by Tubiello et al. (1999). Water cycles in the system through nonlinear, multiplicative interactions (pointed block symbols in Fig. 1), except water flow from soil water to primary storage which is linear process (simple line pathway in Fig. 1).

Sunlight energy drives the natural water system of evaporation from the ocean (k9) and evapotranspiration by plants and soil (k4). For simplification in this kind of minimodel, evaporation and evapotranspiration were modeled as simple functions of storages and sunlight energy; evaporation from the ocean as a function of water in the ocean (OC) and sunlight, and evapotranspiration by plants and soil as a function of soil water (SW) and sunlight. There are many more factors involved in controlling those processes; temperature, saturation vapor deficit, wind, and plant factors such as type of vegetation and their distribution, stage of plant growth, and so on.

Water collected in the primary storage tank through soil drainage is treated using reverse osmosis (RO) to remove particulate matters. Freshwater collected in condensation tanks by reverse osmosis and air handler units (AHU) is returned to the ocean as ocean supply, and to soil as rainfall to close the cycle. 


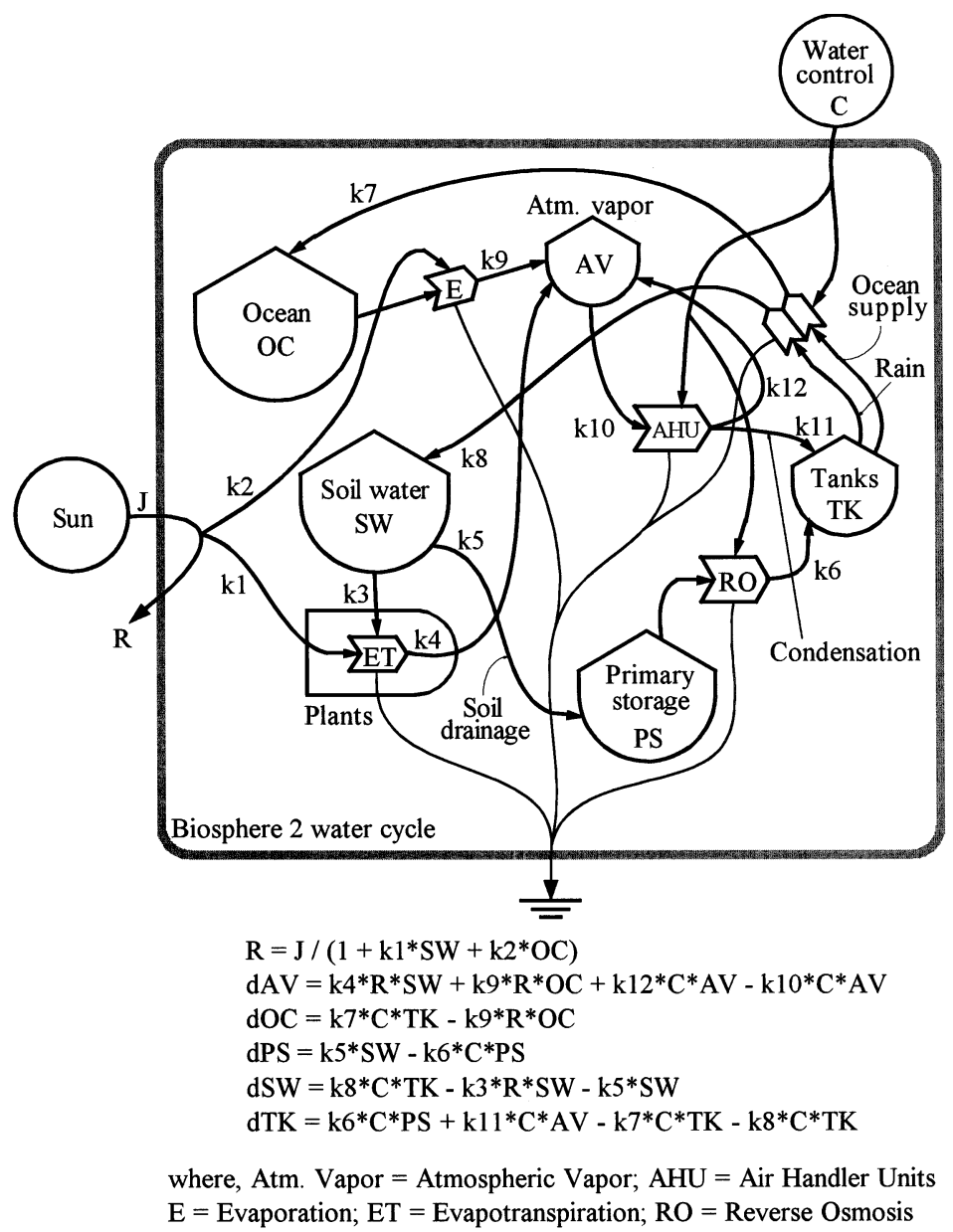

Fig. 1. Energy systems diagram and equations of the Biosphere 2 water cycle. The tank symbol represents storage and the interaction symbols here are multiplication production functions.

The model in Fig. 1 has a pathway (k12) for return of atmospheric vapor which is not condensed in the air handler units, not necessary in the model of Tubiello et al. (1999), but needed herein to represent changes in isotopic fractionation during the condensation process in the air handler units.

\section{Model of stable isotope cycle}

The stable isotope model in Fig. 2 is identical to that of the water cycle in Fig. 1 , except that it has separate reservoirs for each isotopic species of water. This model traces three isotopic components of water, $\mathrm{H}_{2}^{16} \mathrm{O}, \mathrm{HDO}$, and $\mathrm{H}_{2}^{18} \mathrm{O}$. Each 


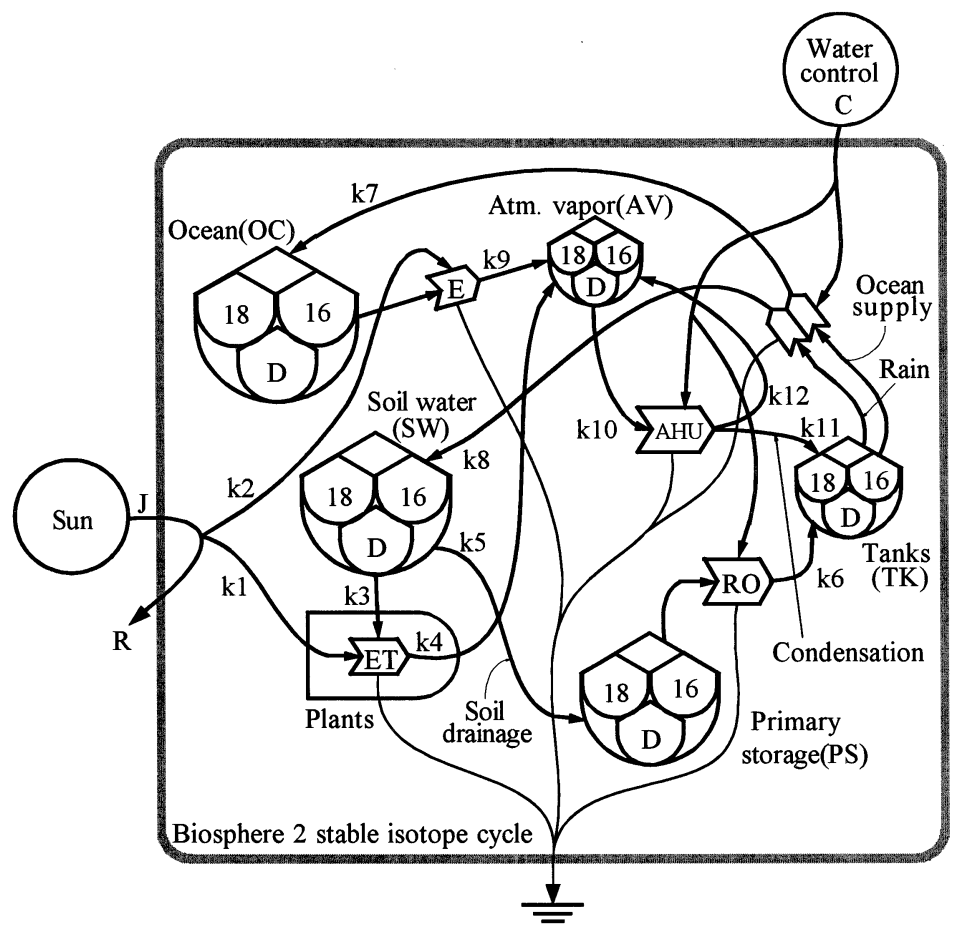

where, Atm. Vapor = Atmospheric Vapor; AHU = Air Handler Units $\mathrm{E}=$ Evaporation; $\mathrm{ET}=$ Evapotranspiration; $\mathrm{RO}=$ Reverse Osmosis; $18=\mathrm{H}_{2}{ }^{18} \mathrm{O} ; 16=\mathrm{H}_{2}{ }^{16} \mathrm{O} ; \mathrm{D}=\mathrm{HDO}$

Fig. 2. Energy systems diagram of the Biosphere 2 stable isotope cycle. Three storage tank symbols are placed within each of the storages in Fig. 1 as a way of showing that the models are parallel differing only in coefficients. Equations for the model are listed in Table 1.

isotopic species has its own pathway coefficients and equations. Equations for the model are listed in Table 1.

Isotopic fractionation occurs in two processes of phase change of water; evaporation of ocean water $(\mathrm{k} 9)$, and condensation of atmospheric vapor in the air handler units (k11). Differences in vapor pressure and molecular diffusivities of different isotopic molecules of water in the air cause fractionation during phase changes (Jouzel et al., 1987). Even though isotopic fractionation factors are dependent on temperature, they were taken as constants for the model with values of 1.074 for ${ }^{18} \mathrm{O}$ and 1.0092 for deuterium (D) as given in Faure (1986).

Reevaporation of rain was assumed to be minor because of high humidity of the atmosphere of Biosphere 2 and short falling distance of raindrops, and thus not included in both the total water model and the isotope model.

Evapotranspiration of soil water $(\mathrm{k} 4)$, another phase change process in the model, was treated as a non-fractionating process, even though water in the 
transpiring leaves undergoes significant enrichment of heavy isotopes. It was assumed that input stem water and transpired water vapor have the same isotope ratios because the ratio of transpiration flux to the amount of water in leaves is high (Wang and Yakir, 1995). Also, the transfer of water from the soil to the root (k3) was considered as an isotopically nonfractionating process (Amundson, 1989).

Movement of water through the soil was treated as a nonfractionating process, because oxygen and hydrogen exchange between water and soil minerals occurs slowly, compared to the time scales considered in the model (Amundson, 1989). Also, reverse osmosis was considered as a nonfractionating process. Slight difference in mass between different water molecules would not affect passage of these molecules under pressure through semi-permeable membranes.

\section{Methods}

\subsection{Calibration}

The energy system diagram in Fig. 1 was calibrated with estimates of storages and flows by Tubiello et al. (1999) (Fig. 3). By putting numbers on pathways and storage 'tanks' in Fig. 3, readers can see at a glance which units have fast or slow rates of turnover. Those values were converted into mass unit for use in the isotope model by assuming the same density of $1 \mathrm{~g} / \mathrm{cm}^{3}$ for all water storages, and were used to calculate the pathway coefficients (Table 2).

Table 1

Difference equations for the stable isotope model in Fig. 2

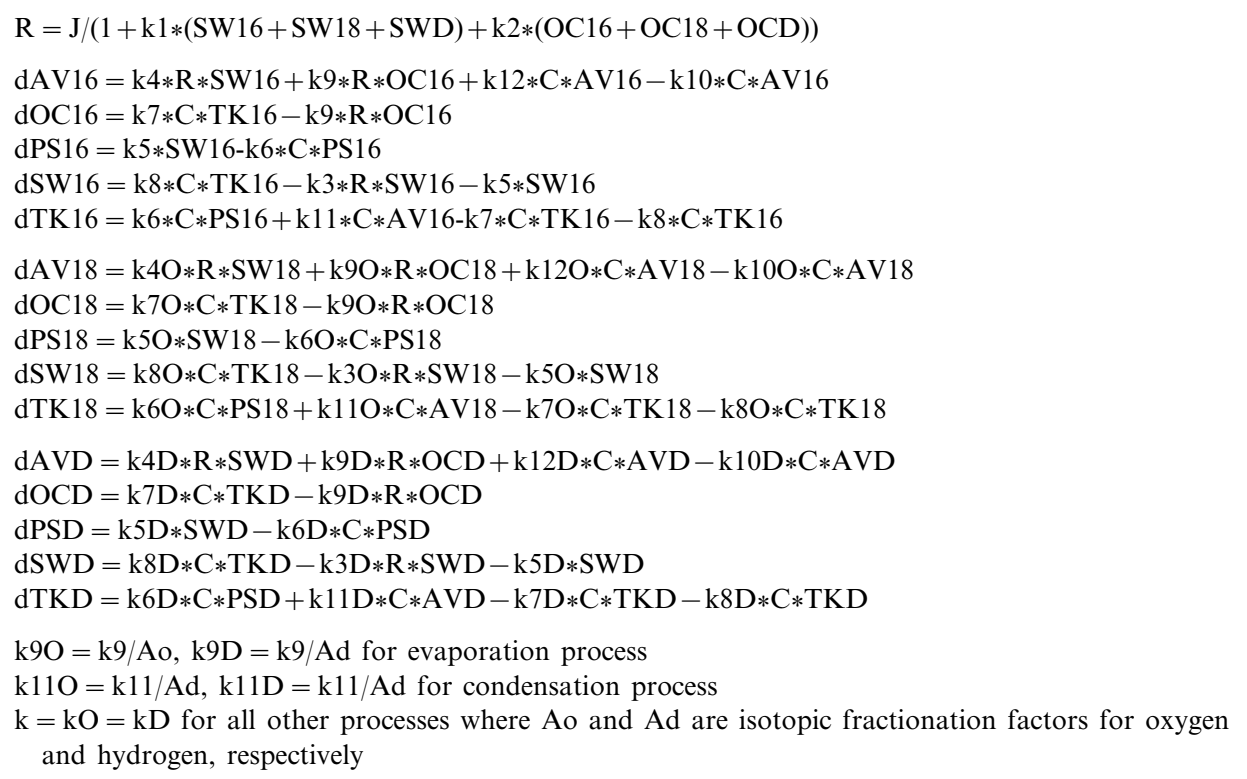




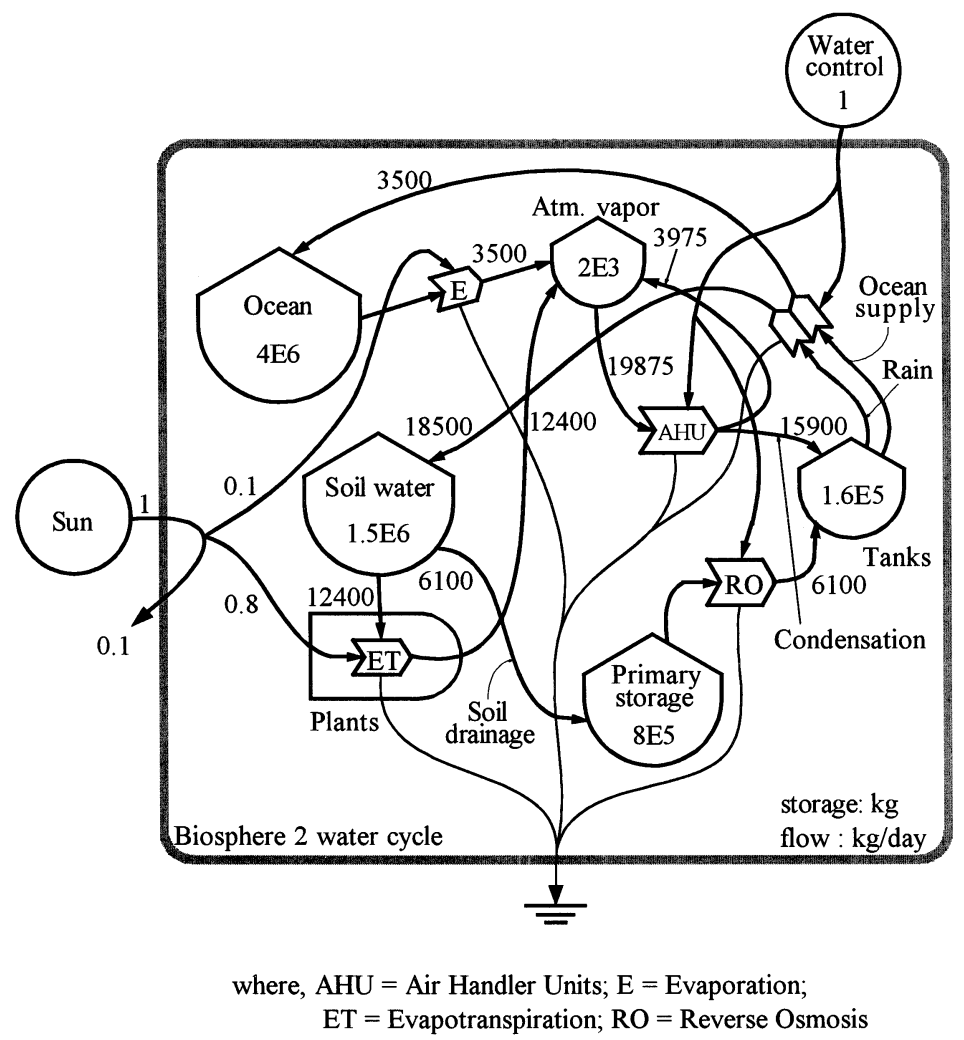

Fig. 3. Energy systems diagram of the Biosphere 2 water cycle in Fig. 1 with flow and storage values for calibration (see Table 2).

The simulation computer program was written in BASIC. The program contains lines for plotting simulation results on the computer screen, initial values of storages and sources, scaling factors for plotting the results, coefficients for the pathways, and difference equations to calculate storage changes over time. The program iterates the simulation for a given time period ( 7 years in this program) with a time step of 0.1 day. Initial values of the storages and sources are put into the computer program as starting points of the simulation.

All the flow values were assumed to be in a steady state for calibration, and some flow values by Tubiello et al. (1999) were adjusted to make steady state. A sine function was used to emulate seasonal variation in sunlight energy. To put seasonal variation in rainfall amount into the simulation model, another sine function was used for outside water control, as a simple first approximation (Linda Leigh, personal communication). A median value of the range given by Tubiello et al. (1999) was used for soil water storage, which has the largest uncertainty in water content inside Biosphere 2. The uncondensed flow (k12) of atmospheric vapor from the air handler units was assumed arbitrarily to be $20 \%$ of total inflow (k10) into 
the units from atmospheric vapor storage. Total inflow (k10) was adjusted so that condensation flow $(\mathrm{k} 11)$ keeps the same value $(1.59 \mathrm{E} 4 \mathrm{~kg} /$ day) specified by Tubiello et al. (1999).

The same calibration values in Table 2 were also used for the isotope model in Fig. 2. The coefficients for $\mathrm{H}_{2}^{16} \mathrm{O}$ are identical to the coefficients for the total water model in Table 2. Coefficients for $\mathrm{H}_{2}^{18} \mathrm{O}$ and $\mathrm{HDO}$ were calculated using the method by McGrane (1998). A BASIC simulation program was used for the isotope model. In this simulation program, isotopic compositions are expressed in the conventional $\delta$ notation, where $\delta^{18} \mathrm{O}$ or $\delta \mathrm{D}=\left(R_{\text {sample }} / R_{\mathrm{SMOW}}-1\right) * 1000 \%$.

$R$ is the ${ }^{18} \mathrm{O} /{ }^{16} \mathrm{O}$ ratio between $\mathrm{H}_{2}^{18} \mathrm{O}$ and $\mathrm{H}_{2}^{16} \mathrm{O}$, or $\mathrm{D} / \mathrm{H}$ ratio between $\mathrm{HDO}$ and $\mathrm{H}_{2}^{16} \mathrm{O}$; SMOW is Standard Mean Ocean Water.

\subsection{Simulation}

The models in Figs. 1 and 2 assume mass conservation of water molecules during simulation. To be consistent with the measured values of $\delta^{18} \mathrm{O}(-0.77$ $\%$ for ocean, $-9.56 \%$ for condensate, and $-14.70 \%$ and $-17.85 \%$ for vapor) in Severinghaus et al. (1994), Severinghaus (1995), a weighted average

Table 2

Calibration of pathway coefficients for computer simulation of the Biosphere 2 water cycle model in Fig. 1

\begin{tabular}{|c|c|c|c|c|}
\hline Item & Expression & Value & Units & Coefficient \\
\hline \multicolumn{5}{|l|}{ Sources } \\
\hline Sunlight & $\mathbf{J}$ & 1 & standard & \\
\hline Water control & $\mathrm{C}$ & 1 & standard & \\
\hline Unused sunlight & $\mathrm{R}$ & 0.1 & $10 \%$ & \\
\hline \multicolumn{5}{|l|}{ Storages } \\
\hline Ocean & $\mathrm{OC}$ & $4.0 \mathrm{E}+06$ & $\mathrm{~kg}$ & \\
\hline Soil water & SW & $1.5 \mathrm{E}+06$ & $\mathrm{~kg}$ & \\
\hline Primary storage & PS & $8 \mathrm{E}+05$ & $\mathrm{~kg}$ & \\
\hline Tanks & TK & $1.6 \mathrm{E}+05$ & $\mathrm{~kg}$ & \\
\hline Atmospheric vapor & AV & $2 \mathrm{E}+03$ & $\mathrm{~kg}$ & \\
\hline \multicolumn{5}{|l|}{ Flows } \\
\hline Plants use of sun & $\mathrm{k} 1 * \mathrm{R} * \mathrm{SW}$ & 0.8 & & $\mathrm{k} 1=5.333333 \mathrm{E}-06$ \\
\hline Ocean use of sun & $\mathrm{k} 2 * \mathrm{R} * \mathrm{OC}$ & 0.1 & & $\mathrm{k} 2=2.5 \mathrm{E}-07$ \\
\hline Soil water uptake by plants & $\mathrm{k} 3 * \mathrm{R} * \mathrm{SW}$ & 12400 & $\mathrm{~kg} /$ day & $\mathrm{k} 3=8.266667 \mathrm{E}-02$ \\
\hline Evapotranspiration & $\mathrm{k} 4 * \mathrm{R} * \mathrm{SW}$ & 12400 & $\mathrm{~kg} /$ day & $\mathrm{k} 4=8.266667 \mathrm{E}-02$ \\
\hline Soil drainage & $\mathrm{k} 5 * \mathrm{SW}$ & 6100 & $\mathrm{~kg} /$ day & $\mathrm{k} 5=4.066667 \mathrm{E}-03$ \\
\hline Reverse osmosis & $\mathrm{k} 6 * \mathrm{C} * \mathrm{PS}$ & 6100 & $\mathrm{~kg} /$ day & $\mathrm{k} 6=0.007625$ \\
\hline Rain & $\mathrm{k} 7 * \mathrm{C} * \mathrm{TK}$ & 3500 & $\mathrm{~kg} /$ day & $\mathrm{k} 7=0.021875$ \\
\hline Ocean supply & $\mathrm{k} 8 * \mathrm{C} * \mathrm{TK}$ & 18500 & $\mathrm{~kg} /$ day & $\mathrm{k} 8=0.115625$ \\
\hline Evaporation from the ocean & $\mathrm{k} 9 * \mathrm{R} * \mathrm{OC}$ & 3500 & $\mathrm{~kg} /$ day & $\mathrm{k} 9=0.00875$ \\
\hline Vapor flow into $\mathrm{AHU}$ & $\mathrm{k} 10 * \mathrm{C} * \mathrm{AV}$ & 19875 & $\mathrm{~kg} /$ day & $\mathrm{k} 10=9.9375$ \\
\hline Condensed vapor in AHU & $\mathrm{k} 11 * \mathrm{C} * \mathrm{AV}$ & 15900 & $\mathrm{~kg} /$ day & $\mathrm{k} 11=7.95$ \\
\hline Uncondensed vapor in AHU & $\mathrm{k} 12 * \mathrm{C} * \mathrm{AV}$ & 3975 & $\mathrm{~kg} /$ day & $\mathrm{k} 12=1.9875$ \\
\hline
\end{tabular}



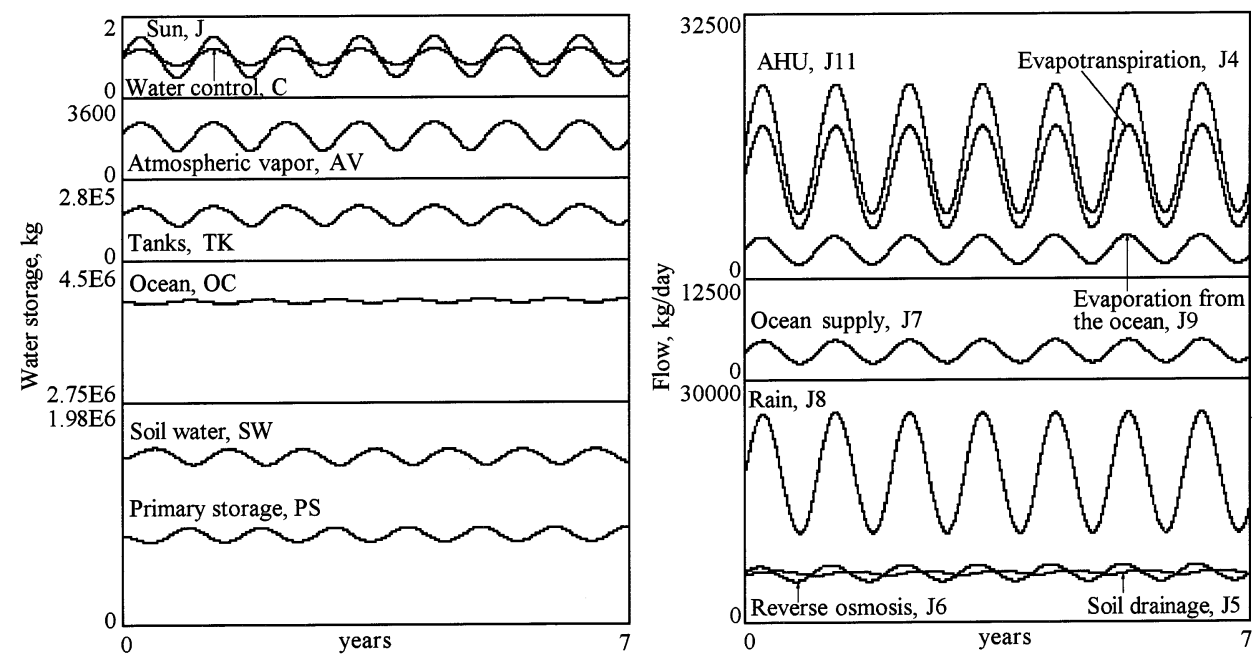

Fig. 4. Simulation result of the Biosphere 2 water cycle model in Fig. 1 with seasonal variation in the water control (C), with coefficients as calibrated in Table 2.

$\left(\delta^{18} \mathrm{O}=-4.12 \%\right)$ was calculated based on their data to use for initial condition for each isotopic water species. The value for condensate was used for soil water, primary storage, and tanks, and the average of two measured values was used for atmospheric vapor, in calculation of the weighted average.

Because there were no data for deuterium concentration, some general relationships between $\delta^{18} \mathrm{O}$ and $\delta \mathrm{D}$ were used to calculate $\delta \mathrm{D}$ of the storages and then to get a weighted average. Meteoric water line $\left(\delta \mathrm{D}=8 \delta^{18} \mathrm{O}+10\right)$ of Craig (1961) cited in Faure (1986) was used for waters in soil, primary storage, and tanks, and deuterium excess of $40 \%$ was used for atmospheric vapor (Jouzel et al., 1987). Deuterium concentration of ocean water was calculated using the relationship of $\delta \mathrm{D}=\mathrm{M} \delta^{18} \mathrm{O}$ (Faure, 1986), where $\mathrm{M}$ is the slope of linear trajectories. Typical value of $\mathrm{M}$ (7.5) in the North Pacific was used for the model in this paper. The resultant values for each category in Severinghaus et al. (1994), Severinghaus (1995) are $-5.78 \%$ for ocean, $-66.48 \%$ for condensate, and $-90.24 \%$ for vapor, and the weighted average is $-28.91 \%$.

\section{Results and discussion}

Fig. 4 shows the simulation result of the water cycle model in Fig. 1. It clearly shows seasonal variation in water storages and flows, except for the ocean with a big storage compared to daily flow values into and out of it. The model result coincides with observed patterns of seasonal variation in the water level of primary storage (Linda Leigh, personal communication): more water in winter than in summer. The simulation result shows about $16 \%$ variation in primary storage between maximum and minimum levels. 
The model result shows that increased sunlight and rainfall during the Summer season circulates more water through the fast pool of the air handler's condensation system and evapotranspiration, decreasing water quantity stored in primary storage. The fast pool also shows more definite seasonal variation than those of the medium and slow pools. Decrease in sunlight and rainfall in Winter causes less water cycled through the fast pool, increasing the amount of water stored in primary storage.

Soil water and primary storage show a time lag in their maximum and minimum levels compared to seasonal variation of other storages and flows. With relatively constant soil drainage, increase in freshwater supply through the reverse osmosis system to meet rainfall requirement decreases the water level in primary storage. Combined with decreased soil drainage, this seems to cause the time lag in the seasonal variation. Soil water content reaches its maximum level after the evapotranspiration rate starts to decrease by decreasing sunlight energy and rain amount.

Effect of water management on the water cycle in Biosphere 2 was investigated by making the water control (C) constant over the simulation period. Changes in water management mostly affected the level of the primary storage (PS), and flows in (J5) and out (J6) of it. But, it did not have much effect on other storages and flows, implying that variation in sunlight energy can account for the seasonal water cycle in Biosphere 2.

Fig. 5 shows the simulation result of the isotope model in Fig. 2, at initial condition of $\delta^{18} \mathrm{O}=-4.12 \%$ and $\delta \mathrm{D}=-28.91 \%$ for all water storages. Isotopic composition of the storages reaches steady state, and the steady state values of $\delta^{18} \mathrm{O}$
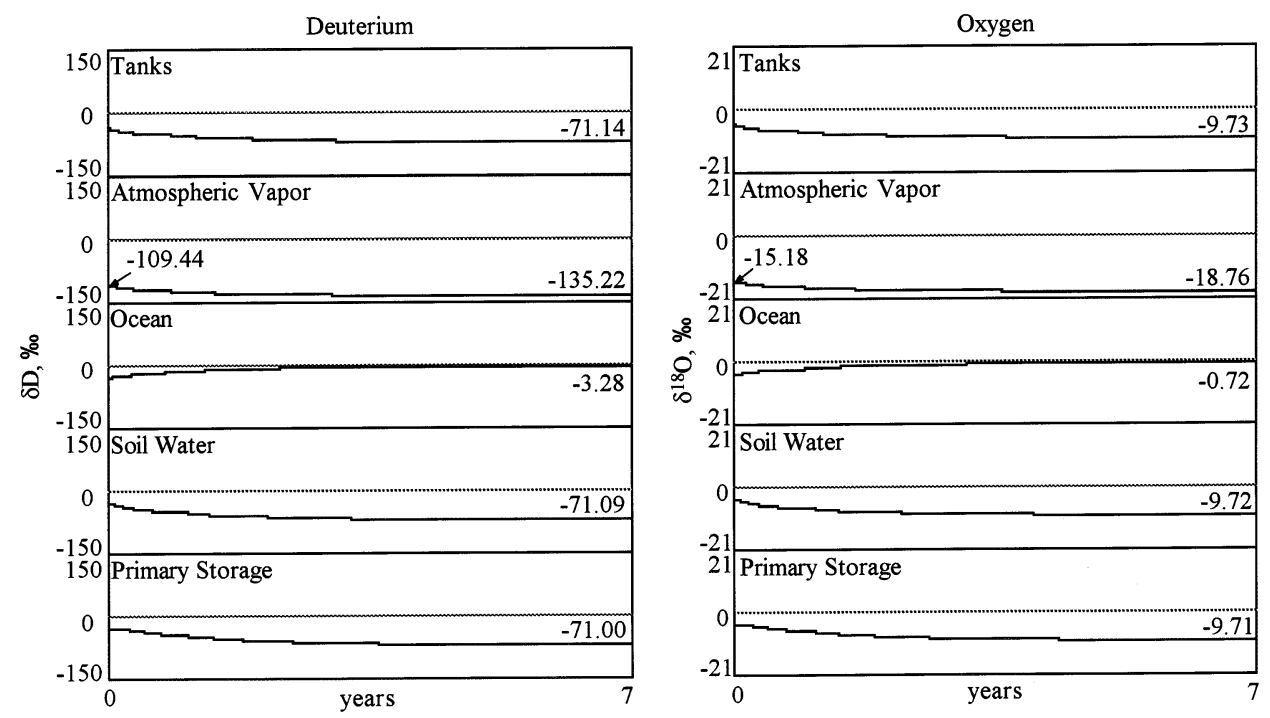

Fig. 5. Simulation result of the Biosphere 2 stable isotope model in Fig. 2, at initial condition of $\delta^{18} \mathrm{O}=-4.12 \%$ and $\delta \mathrm{D}=-28.91 \%$ for all water storages. Numbers on the right side of both graphs represent isotopic compositions at steady state. 


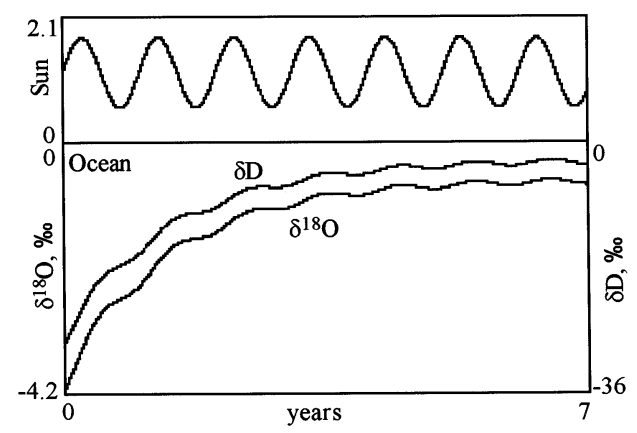

Fig. 6. Expanded view of variation in isotopic concentrations of the ocean water in Fig. 5, shown with seasonal variation of sunlight energy.

of the storages are close to the measured values in Severinghaus et al. (1994)and Severinghaus (1995). The result clearly shows the natural trend of isotopic concentration, heavy isotope concentrations decreasing in the order: ocean $>$ freshwater $>$ atmospheric vapor. Isotopic concentrations of atmospheric vapor instantly drop from its initial value of $\delta^{18} \mathrm{O}=-4.12 \%$ and $\delta \mathrm{D}=-28.91 \%$ to $\delta^{18} \mathrm{O}=-15.18$ $\%$ and $\delta \mathrm{D}=-109.44 \%$ due to its fast turnover time.

Fig. 6 shows an expanded view of isotopic concentration of the ocean, with seasonal variation of sunlight energy. Ocean and atmospheric vapor are two storages that would be affected by seasonal variation in sunlight energy, because they are the storages with isotopic fractionation processes in the model in Fig. 2. Ocean water shows seasonal variation in both isotopic concentrations with a time lag. The variations are about $13 \%$ for oxygen isotope and $22 \%$ for hydrogen isotope at steady state. Unlike the ocean, atmospheric vapor showed little seasonal variation because of its fast turnover time.

The simple model in Fig. 1 shows the observed patterns of water circulation in Biosphere 2 with sunlight energy the driving force in seasonal variations. The simulation supports the analyses of the Biosphere 2 water cycle given by Tubiello et al. (1999), and expands their work by including the simulations of the trends of isotopic fractionation in the combined water system, natural and mechanical, inside Biosphere 2.

Energy systems diagrams help to understand material flows and energy transformations at the same time, helping derive and visualize systems equations. As illustrated in Fig. 2, isotopes can be included making it easy to generate the parallel sets of equations for separate but concurrent simulation of the isotopes after which ratios are computed.

\section{Acknowledgements}

I acknowledge suggestions from Linda Leigh, Guy McGrane, and Dr Bruno Marino. This work was assisted by a contract between Space Biospheres Ventures (Biosphere 2) and the University of Florida, H.T. Odum principal investigator. 


\section{References}

Amundson, R., 1989. The use of stable isotopes in assessing the effect of agriculture on arid and semi-arid soils. In: Rundel, R.W., Ehleringer, J.R., Nagy, K.A. (Eds.), Stable Isotopes in Ecological Research. Springer-Verlag, New York, pp. 318-341.

Craig, H., 1961. Isotopic variations in meteoric waters. Science 133, 1702-1703.

Faure, G., 1986. Principles of Isotope Geology. Wiley, New York, p. 589.

Gat, J.R., 1980. The isotopes of hydrogen and oxygen in precipitation. In: Fritz, P., Fonts, J.Ch. (Eds.), Handbook of Environmental Geochemistry. Elsevier, Amsterdam, pp. 21-47.

Jouzel, J., Russell, G.L., Suozzo, R.J., Koster, R.D., White, J.W.C., Broecker, W.S., 1987. Simulations of the $\mathrm{HDO}$ and $\mathrm{H}_{2}^{18} \mathrm{O}$ atmospheric cycles using the NASA GISS general circulation model: the seasonal cycle for present-day conditions. J. Geophys. Res. 92 (D12), 14739-14760.

McGrane, G., 1998. Simulating whole-earth cycles using hierarchies and other general systems concepts. Ph.D. Dissertation, Department of Environmental Engineering Sciences, University of Florida, Gainesville, FL.

Severinghaus, J.P., Broecker, W.S., Dempster, W.F., MacCallum, T., Wahlen, M., 1994. Oxygen loss in Biosphere 2. Trans. Am. Geophys. Union 75 (3), 35-37.

Severinghaus, J.P., 1995. Studies of the terrestrial molecular oxygen and carbon cycles in sand dune gases and in Biosphere 2. Ph.D. thesis, Columbia University, New York.

Tubiello, F.N., Druitt, J.W., Marino, B.D.V., 1999. Dynamics of the global water cycle of Biosphere 2. Ecol. Eng. 13, 287-300.

Wang, X.F., Yakir, D., 1995. Temporal and spatial variations in the oxygen-18 content of leaf water in different plant species. Plant Cell Environ. 18, 1377-1385. 